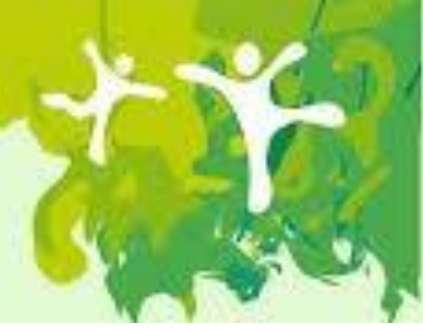

\title{
CARACTERISTICAS CLINICAS E LABORATORIAIS DE NEONATOS COM LESAO RENAL AGUDA
}

\section{Pôster}

Autores deste trabalho:

Maria Cristina de Andrade: UNIFESP-EPM

Haquim rI[[ Haquim RP: UNIFESP-EPM

Carvalhaes JTA : UNIFESP-EPM

Balda R : UNIFESP-EPM

Cancado MA : UNIFESP-EPM

Mello F : Hospital e Maternidade Santa Joana

Área do Trabalho: Pediatria

Número de inscrição: 5597

Data da submissão:01/09/2016 às 10:03

\section{Justificativa}

A lesão renal aguda (LRA) é doença de grande impacto nos índices de mortalidade e morbidade neonatal.

\section{Objetivo(s)}

elaborar perfil epidemiológico do neonato com LRA, em diálise peritoneal (DP). Através da análise de dados gestacionais, fatores de risco maternos, e patologias do recém-nascido (RN) objetivou-se estabelecer correlação para os estágios dessa doença por escores próprios pediátricos (pRIFLE).

\section{Método(s)}

estudo descritivo, retrospectivo e prospectivo, com base nos prontuários, dos $\mathrm{RN}$ com LRA em DP entre 01/2003 e 05/2014 em hospital terciário. Foram verificados valores de creatinina e mensuração da diurese antes e no diagnóstico de LRA (início da DP), para cálculo do pRIFLE (risco para lesão renal, injúria, falência da função renal, perda da função renal, doença renal terminal).

\section{Resultado(s)}


$24 \mathrm{RN}$ foram submetidos a DP, com média de idade gestacional de 31 sem, peso de $1.744 \mathrm{~g}$, sendo $62,5 \%$ masc. $75 \%$ foram partos cesarianos. Em $66,7 \%$ havia presença de doença. Etilismo foi presente em $12,5 \%$ e tabagismo em 20,8\%. Na LRA, 45,8\% tinham como etiologia insuficiência respiratória, $29,2 \%$ asfixia e $25 \%$ malformações congênitas renais. Tipo de lesão: 79,2\% eram inicialmente pré-renal e 79,2\% tiveram sepse. À internação, 33,3\% foram submetidos a cirurgia, 95,8\% ventilação mecânica. $100 \%$ usaram cateter, drogas nefrotóxicas, diuréticos e drogas vasoativas. Antes do diagnóstico de LRA o clearance de creatinina era alterado em $75 \%$ dos pacientes neonatos, e oligúria maior que 12 horas em 41,7\%. Quanto a classificação dos pacientes nos critérios do pRIFLE, antes do diagnóstico 33,3\% pertenciam ao pRIFLE de falência da função renal, 8,3\% ao de Lesão renal, 33,3\% com risco para lesão e 8,3\% sem lesão. Após diagnóstico, $75 \%$ da amostra pertencia ao grupo de falência da função renal e $25 \%$ com lesão renal. Considerando-se a classificação do pRIFLE no diagnóstico à presença de oligúria maior que 12 horas, observou-se que nos casos de falência renal, 55,6\% eram oligúricos enquanto nenhum paciente com pRIFLE de lesão renal era oligúrico (p: 0,022).

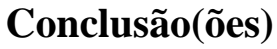

O diagnóstico de lesão renal mais precoce através dos meios atualmente disponíveis (classificação do pRIFLE) deve ser realizado para se instituir terapêutica adequada, diminuindo desfechos desfavoráveis 